\title{
Restoration of Shoulder Range of Motion
}

\author{
Jung-Man Kim \\ Department of Orthopaedic Surgery, Korea Juseok Hospital, Suwon, Korea
}

Looking at the last issues of Clinics in Shoulder \& Elbow, by Back et al. and Park et al., all report somewhat alarming rate of stiffness after rotator cuff tear and reverse shoulder arthroplasty, respectively. Rotator cuff repairs with anchors, fracture fixations, or labral repairs with anchors; all of these treatment needs sacrifice of range of shoulder motion for a certain period of time. Currently we are making our shoulder stiffer than ever due to the fact that failure of these repairs or reductions are considered "failures," whereas postoperative stiffness is considered "complication but not failure."

Adhesive capsulitis combined with these shoulder pathologies needs even longer time to recover shoulder full range of motion (ROM), up to several years with painful rehabilitation process. Moreover, we have experienced even permanent incomplete recovery compared to the unaffected side for ROM. Restoration of shoulder ROM after surgery and treatment of adhesive capsulitis or other causes of partial ankylosis have been a challenging issue since beginning of the shoulder surgery. Current rehabilitation programs are difficult and time consuming procedure for the patients and the surgeons.

Here I believe that we can find one solution to shoulder stiffness. Axillary nerve block in combination with suprascapular nerve block is not sufficient for the manipulation of stiff shoulder although it may play a role in reducing pain. Ultrasonography guided regional block such as C5, 6 nerve root block at out patient department may be a simple, effective and safe method in my experience. The author would like to suggest the members of our Korean Shoulder and Elbow Society to pay attention to regional cervical nerve block for treating and restoring shoulder ROM. It could be a simple, effective and cost-effective technique to restore ROM in stiff shoulder of any causes.

Correspondence to: Jung-Man Kim

Department of Orthopaedic Surgery, Korea Juseok Hospital, 159 Changnyong-daero, Jangan-gu, Suwon 440-814, Korea

Tel: +82-1688-5030, Fax: +82-31-251-7703, E-mail: osjmk33@naver.com

Financial support: None. Conflict of interests: None. 